\title{
Secondary circulation within a tropical cyclone observed with L-band wind profilers
}

\author{
M. Teshiba ${ }^{1}$, M. D. Yamanaka ${ }^{2,3}$, H. Hashiguchi ${ }^{1}$, Y. Shibagaki ${ }^{4}$, Y. Ohno ${ }^{5}$, and S. Fukao ${ }^{1}$ \\ ${ }^{1}$ Research Institute for Sustainable Humanosphere, Kyoto University, Uji, Kyoto 611-0011, Japan \\ ${ }^{2}$ Graduate School of Science and Technology, Kobe University, Kobe 657-8501, Japan \\ ${ }^{3}$ Institute of Observational Research for Global Change, Japan Agency for Marine-Earth Science and Technology, \\ Yokohama 236-0001, Japan \\ ${ }^{4}$ Osaka Electro-Communication University, Neyagawa, Osaka 572-8530, Japan \\ ${ }^{5}$ National Institute of Information and Communications Technology, Koganei, Tokyo 184-8795, Japan
}

Received: 3 December 2003 - Revised: 4 June 2004 - Accepted: 21 June 2004 - Published: 29 November 2004

Part of Special Issue "10th International Workshop on Technical and Scientific Aspects of MST Radar (MST10)"

\begin{abstract}
In association with the passage of a Tropical Cyclone (TC) around Japan, the secondary circulation in the region from the outer side to the center was investigated in detail by two separately located L-band wind profilers and the rawinsonde observations from 1 to 2 October 2002, for the first time. As the wind profilers can observe wind fields not only within rainbands but also in between, the mesoscale wind circulation including the vertical wind component in wide areas from the lower layer to the upper layer was investigated.
\end{abstract}

While the TC center approached the profiler stations, several rainbands associated with the TC subsequently passed. Relatively warm, moist inflow with a cyclonic rotation was observed in the lower-troposphere while the TC center approached. The inflow reached the inside of the main rainband where the updraft was observed. Above 5-km height (with temperature below $0^{\circ} \mathrm{C}$ ), outflow and weak downdraft corresponding to falling frozen particles were observed. It is considered that the frozen particles formed precipitating clouds mainly in the outer rainband region. The continuous wind circulation transported water vapor from the lower troposphere to the upper troposphere via the vicinity of TC center.

On the other hand, after the passage of the TC center, the developed rainband passed, which was located in the south and southwest quadrant of the TC. It is suggested with the profilers' data that the rainband was intensified mainly by warm and moist outflow below 3-km height.

Key words. Meteorology and atmospheric dynamics (mesoscale meteorology, convective processes, precipitation)

Correspondence to: M. Teshiba

(teshiba@ rish.kyoto-u.ac.jp)

\section{Background}

Observational studies of Tropical Cyclones (TC) by surface meteorological instruments, balloons, airborne (Jorgensen, 1984a, b; Marks et al., 1987; Powell, 1990a, b; Ryan et al., 1992; Harr and Elsberry, 1996) and ground-based Doppler radars (Sakakibara et al., 1985; Ishihara et al., 1986; Tabata et al., 1992) have made substantial contributions to the understanding of TC's structure and dynamics. Jorgensen (1984a, b) reported the precipitating clouds of eyewall, a stratiform rain region, and rainbands, which were observed by an airborne radar mainly within a radius of $150 \mathrm{~km}$ from TC center.

Marks et al. (1987) pointed out that the primary circulation was characterized by a core of maximum tangential wind, while the secondary circulation in radius-height cross section was characterized by a lower tropospheric layer with inward directed flow and a layer of intense radial outflow from the eyewall concentrated at upper levels. These characteristics agree well with theoretical studies by Shapiro and Willoughby (1982) and others. Airborne radars and groundbased Doppler radars can reveal the inner structure of TC, however, the observation is limited to narrow area and cannot be conducted if there is no rain in the observation area. On the other hand, wind profilers continuously enable direct observations of radial, tangential, and vertical wind components even under the clear-air condition. As a result, provided the time-space conversion is applied, the detailed wind behavior is obtained in wide areas. Shibagaki et al. (2003) showed detailed distributions of tangential and radial winds to examine some mesoscale circulations existing in a TC, with observations by the Middle and Upper (MU) atmosphere radar. Moreover, if simultaneous observations of a TC are conducted with multiple spatially-separated wind profilers, even mesoscale disturbances within a TC and their rapid changes can also be investigated by comparing the data between the stations. 
Table 1. Specification of the Lower Troposphere Radar (LTR) of WINDAS.

\begin{tabular}{ll}
\hline Operational Frequency & $1357.5 \mathrm{MHz}$ \\
Peak Power & $3 \mathrm{~kW}$ \\
Beam Width & $3^{\circ}$ \\
Antenna & Phased Array System \\
Antenna Aparture & $16 \mathrm{~m}^{2}$ \\
Beam Direction & $(\mathrm{Az}, \mathrm{Ze})=(0.0),(0.15),(90.15)$, \\
& $(180.15),(270.15)$ \\
Time Resolution & $1 \mathrm{~min}$ \\
Height Resolution & $300 \mathrm{~m}$ \\
\hline
\end{tabular}

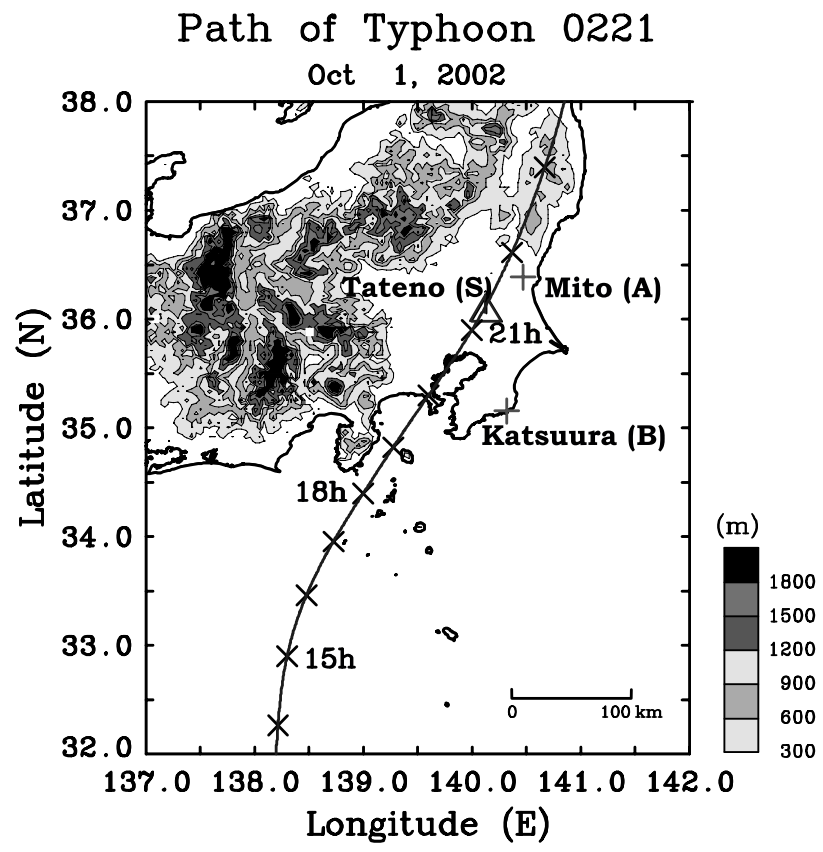

Fig. 1. The trajectory of TC Higos $(0221)$. Cross $(x)$ signs indicate the position of the TC center every hour. Plus $(+)$ and triangle $(\triangle)$ signs indicate the positions of the two WINDAS stations and the radiosonde observatory, respectively. The distance and time of the TC center closest to Mito (A) WINDAS station were about $13 \mathrm{~km}$ and 21:40 LT, respectively. In the case of the Katsuura (B) station, the distance and time of closest approach were $80 \mathrm{~km}$ and 20:10 LT, respectively. The Tateno (S) radiosonde station was located about $50 \mathrm{~km}$ southwest of Mito (A). A topographical map around the Kanto plain is also indicated.

We consider that detailed wind variations around TC center need to be investigated with observational data, but there is often no rain, and any observation except that of wind profilers cannot show wind variations with high time and height resolution. The resolutions provided by numerical simulations are not sufficient to investigate the detailed wind changes in a TC center region. The TC, Typhoon 0221 (Higos), passed across Japan on 1 to 2 October 2002, preserving its strong primary vorticity. In Japan, thirty-one L-band $(1.3 \mathrm{GHz}$ frequency) wind profilers have been operated by

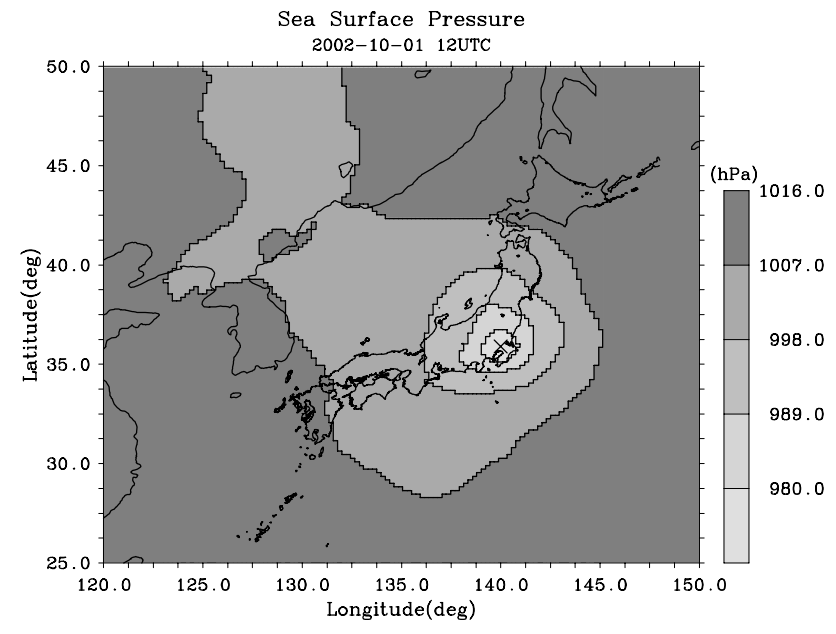

Fig. 2. Sea surface pressure at 21:00 LT on 1 October 2002, provided by JMA. The cross $(x)$ sign indicates the position of the TC center.

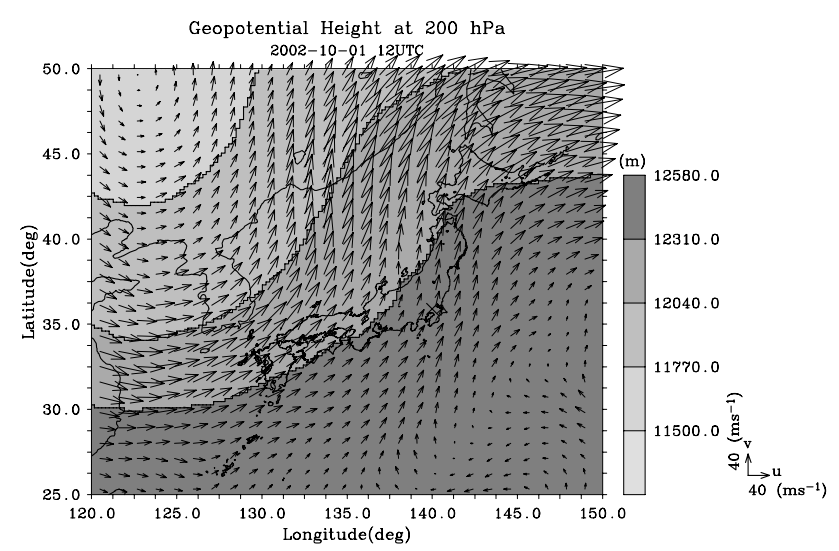

Fig. 3. Same as Fig. 2 except for geopotential height (contour) and horizontal wind (arrows) at $200 \mathrm{hPa}$.

the Japan Meteorological Agency (JMA) since June 2002. While the TC moved along the Japan Islands, some of the wind profilers could observe the associated wind field. In particular, since there was no rain within a radius of about $100 \mathrm{~km}$ from the TC center at Mito $\left(36.38^{\circ} \mathrm{E}, 140.47^{\circ} \mathrm{N}\right.$, $29 \mathrm{~m}$ in MSL) and Katsuura $\left(35.15^{\circ} \mathrm{E}, 140.31^{\circ} \mathrm{N}, 12 \mathrm{~m}\right.$ in MSL) stations, the circulations corresponding to the TC could be investigated only using the operational wind profiler data.

This paper describes the kinematic structure of the TC, Typhoon Higos (0221), by using various observational data on 1 to 2 October 2002. Additionally, the circulation from lower to upper heights is discussed in the context of the profilers' observations of the vertical wind motion, as well as the horizontal wind components. 

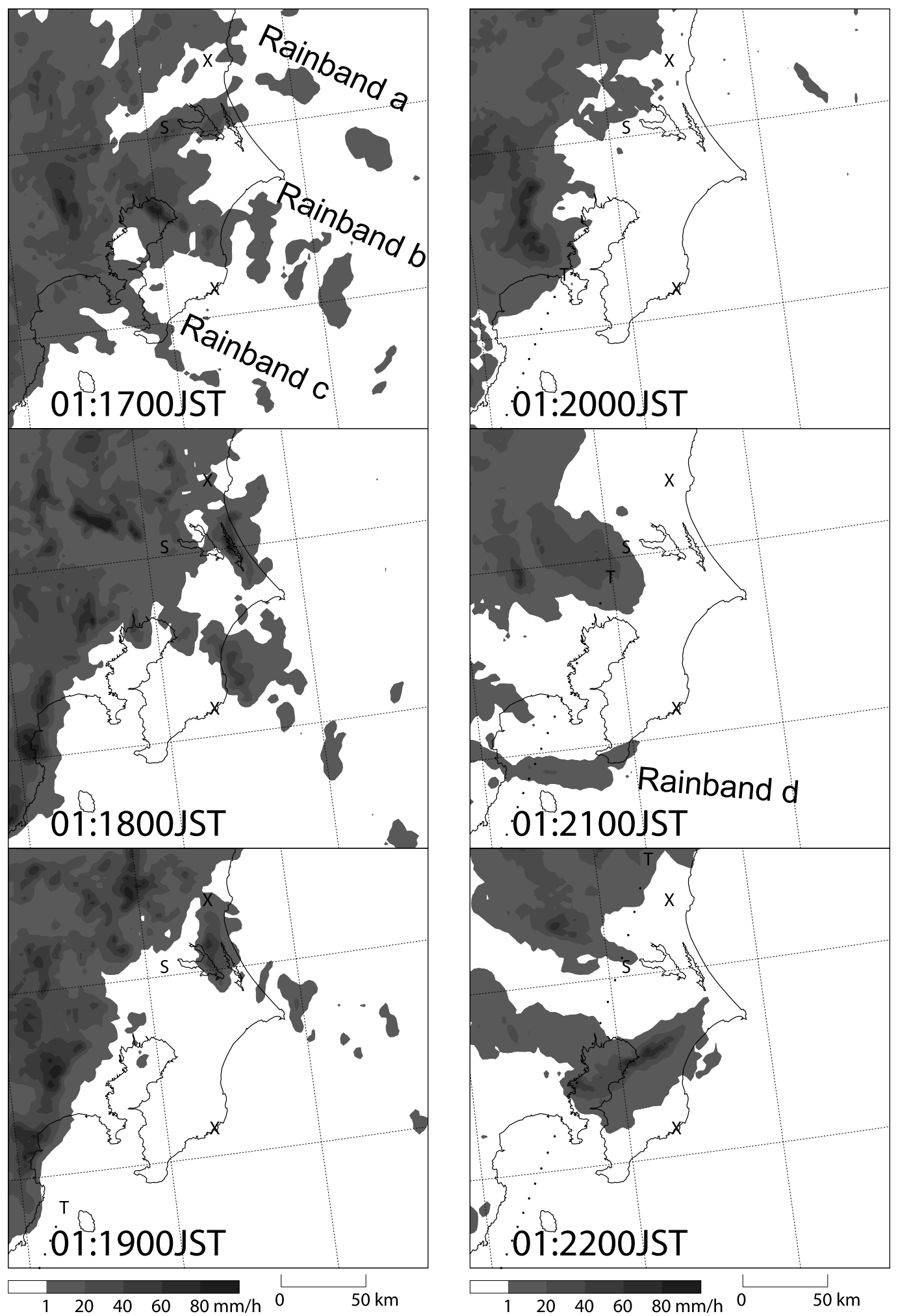

Fig. 4. Hourly maps of C-band radar reflectivity at the 2-km level observed during the period 17:00 to 22:00 LT. The two WINDAS stations and the radiosonde observatory are indicated by cross $(x)$ and " $S$ " signs, respectively. The TC center is shown by a " $T$ " sign. 


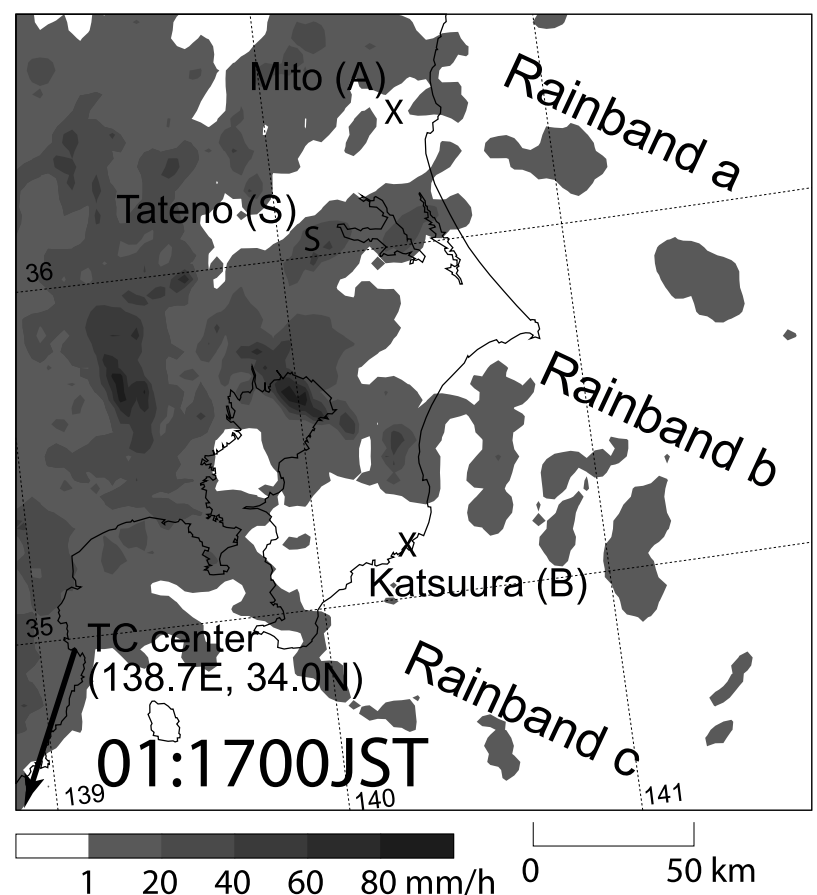

Fig. 5. C-band radar reflectivity at the $2-\mathrm{km}$ level in the Kanto Plain observed at 17:00 LT. The main rainbands associated with the TC are also shown.

\section{Observation data}

The two L-band $(1.3 \mathrm{GHz})$ wind profilers, parts of WINDAS (Wind profiler Network and Data Acquisition System; Ishihara and Goda, 2000; Ishihara et al., 2003) of the Japan Meteorological Agency (JMA), are able to show the wind field from the outer rainband to the storm center in detail. We used the two wind profilers' data because the two profilers did not observe not the orographic rainbands, but rather they observed the TC associated ones. The specification of the radars is shown in Table 1. The horizontal wind component is calculated from the oblique beams of opposite directions. Moreover, operational C-band $(5.6 \mathrm{GHz})$ meteorological radar and radiosonde data are used to show the relationship between wind behavior and rainbands. Rawinsonde observations were also conducted at Tateno near the two profilers' stations to obtain some profiles of temperature and humidity.

A topographic map around the Kanto Plain in the eastern Japan, and the locations of the two profilers (Mito and Katsuura) and a radiosonde station (Tateno) are shown in Fig. 1. The Kanto Plain, whose area is about $150 \mathrm{~km} \times 150 \mathrm{~km}$, is surrounded by mountains on the west and north sides.

The horizontal wind velocity relative to a TC center on the surface is examined by the speed of the TC movement estimated from the spline interpolation of the locations of the TC center, which were reported by JMA every one or three hour(s). Then, the horizontal wind is applied to the cylindrical coordinates relative to the TC center, and decomposed into the radial and tangential wind components.
Wind profilers provide a vertical profile of three components of the wind velocity vector below about $7-4 \mathrm{~km}$ height continuously with high time and range resolutions under clear-air conditions. The existence of precipitating particles as scatters for radar beams makes it possible to infer horizontal wind components up to the higher height of about $10 \mathrm{~km}$ than that under clear-air conditions. However, as for the vertical wind component, the wind profiler detects not only the vertical wind of the air but also the falling speed of precipitating particles because high frequency radars are more sensitive to the particles than the clear air. If an observed vertical wind component is negative (downdraft) and the echo intensity is large, it is considered that the negative vertical wind is mainly caused by the falling speed. In this study, a positive vertical wind is considered to be an updraft, but a negative wind cannot be identified as either a downdraft or falling rain particles. Even admitting this defect, the data are important to examine characteristics of water circulation associated with TC.

\section{Synoptic situation and rainband distribution}

\subsection{Large-scale structure of TC}

The moving path of the TC is shown in Fig. 1. The TC came from the south of Japan, and moved to the north. The profiler stations concerned with this study are located on the flat plain (as shown in Fig. 1), and the southeasterly wind in approaching the TC is mainly observed, where the wind blows from the ocean. Therefore, the observed echoes were not affected or forced by mountains, but caused by the TC. The central pressure of the TC reported by JMA was $960 \mathrm{hPa}$ at landfall and $965 \mathrm{hPa}$ at 21:00 LT (Local Time $=$ UTC +9 ) on $1 \mathrm{Oc}-$ tober 2002 (Fig. 2). The mid- and upper-tropospheric trough was located in the East China Sea, as shown in Fig. 3. The northeastward jet stream flew in the Japan Sea, about a thousand kilometers northwest of the TC center. The trough extended from the Chinese continent to the East China Sea, and was nearly stagnant for the next six hours. The TC moved into the baroclinic zone of the trough.

\subsection{Rainband structure}

The rain distribution in Fig. 4 shows three distinct rainbands on the eastern side of the outer and inner rainband (the northeast quadrant of the TC center). A part of socalled "Delta Rain Shield" (Willoughby et al., 1984) is distributed widely in the west of the Kanto plain. Another rainband (d) was observed in the southwest quadrant of the TC. The detailed structures of these rainbands are distinguished in Fig. 5. The main rainbands ( $a, b$, and c) extended in the northwest-southeast direction, perpendicular to the moving direction of the TC center on the ground. The rainbands had some ten kilometer width and some hundred kilometer length. The individual precipitating clouds were also embedded in the rainbands. Rainband $\mathrm{b}$ and $\mathrm{c}$ merged into one 

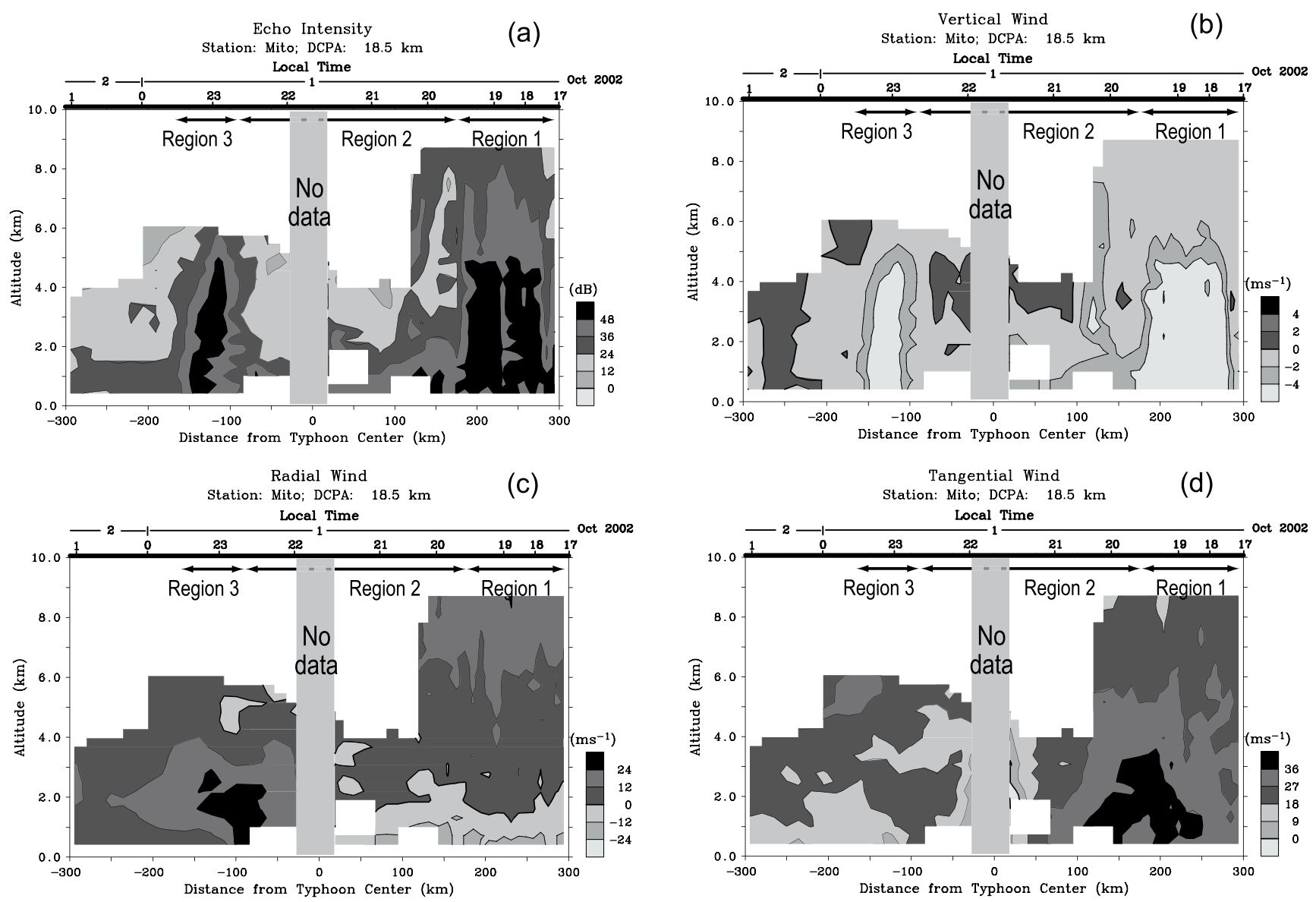

Fig. 6. Radius-height cross-sections of (a) echo intensity, (b) vertical wind, (c) radial wind, and (d) tangential wind components at Mito (A) station. Positive values of vertical, radial, and tangential wind indicate updraft, outflow, and cyclonic wind, respectively. A positive (negative) value of radius of the TC center corresponds to the period when the TC approaches (leaves). There is no data observed within 18 $\mathrm{km}$ in distance because the distance is that the TC approached closest to the observatory.

around 18:00-19:00 LT as they moved northeastward. Rainband $\mathrm{c}$ before merging is associated with the inner rainband of the TC (Willoughby et al., 1984).

\section{Characteristics of storm-relative wind behavior}

Radius-height cross sections of signal-to-noise (SN) ratio (referred to as "echo intensity") of the vertical beam, vertical wind, storm-relative radial and tangential wind components are used in Figs. 6 and 7 to investigate wind changes associated with the TC and rainbands. The distance closest to the TC center approach at Mito and Katsuura is about 18.5 and $64.5 \mathrm{~km}$, respectively. Therefore, the wind behavior within the distance cannot be observed. A positive (negative) value of the radius of the TC center means that the TC approaches (leaves) the respective stations. The periods during which the TC approaches and leaves the stations are referred to as the period "in the front side" and "in the rear side", respectively. Characteristics of the wind changes during the passage of the rainbands are analyzed in the Regions labelled 1-3. The fluctuating components of the horizontal wind relative to the TC center are included in the time change of the TC, as well as the asymmetric structure.

The main rainbands passed Region 1, one after another, and seemed to consist of convective precipitating clouds because strong reflectivity echo extended vertically. Figure $6 c$ indicates that inflow and outflow are seen below and above $2 \mathrm{~km}$ height, respectively, while the TC was approaching the radar site. Similar features of radial wind were found in Fig. 7, and also reported by Jorgensen (1984a), Tabata et al. (1992), Teshiba et al. (2001), and Shibagaki et al. (2003). Cyclonic winds gradually became stronger in time over both stations, and, in particular, the horizontal gradient of the cyclonic wind was large in the main rainbands, that is the rainbands were developed where the horizontal shear of the cyclonic wind was strong. On the other hand, the vertical gradient was small relative to the horizontal one. As shown in Fig. 6, the maximum cyclonic wind was seen in the inner edge of Region 1 during the period 19:00 to 21:00 LT, especially below $3 \mathrm{~km}$ height. The strong echo region extended vertically, not like the outward slope, as represented by Jorgensen (1984a). The strong radar reflectivity in Region 1 was 

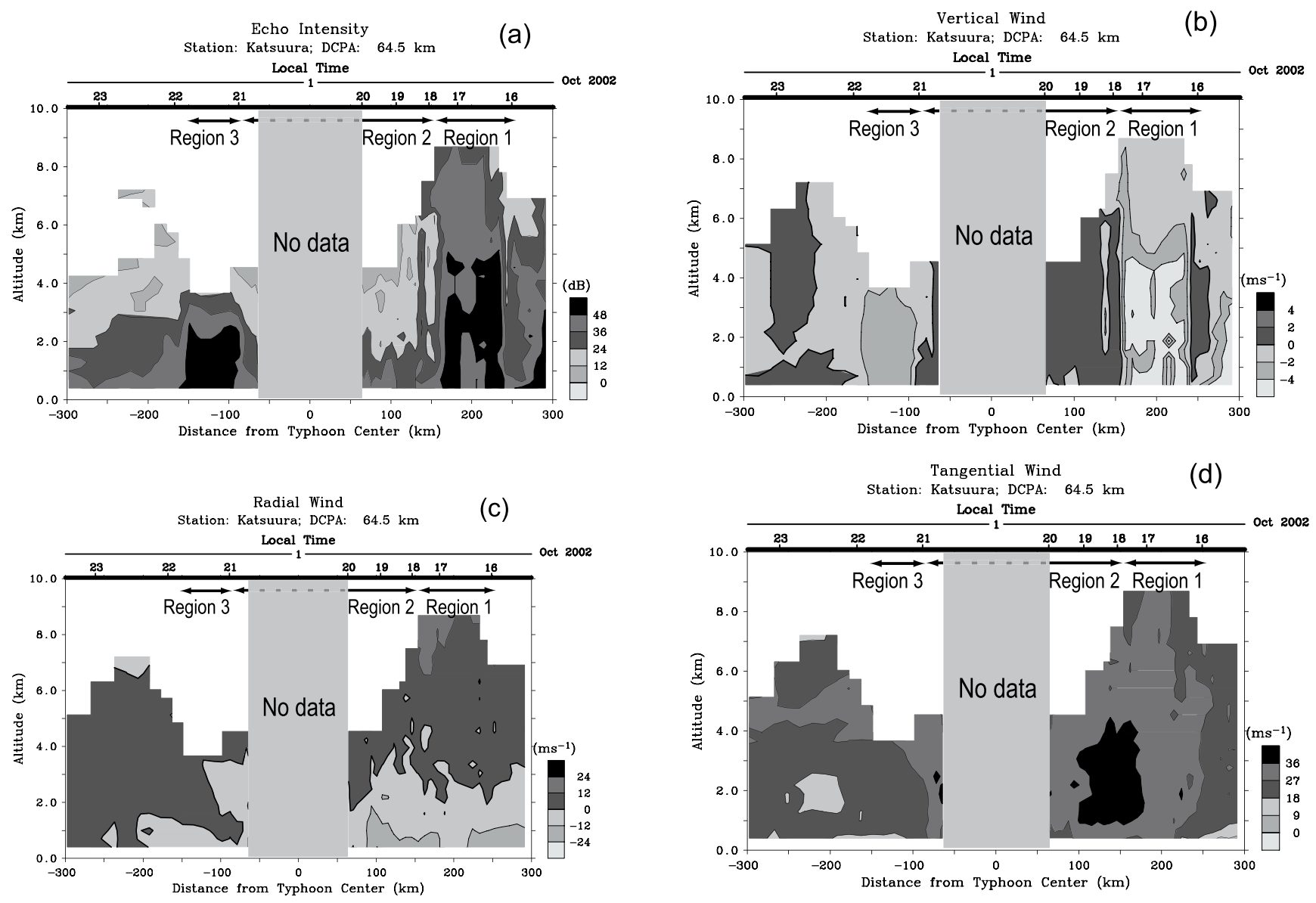

Fig. 7. Same as Fig. 6 but for the results at Katsuura (B) station. There is no data observed within $65 \mathrm{~km}$ in distance.

(a)

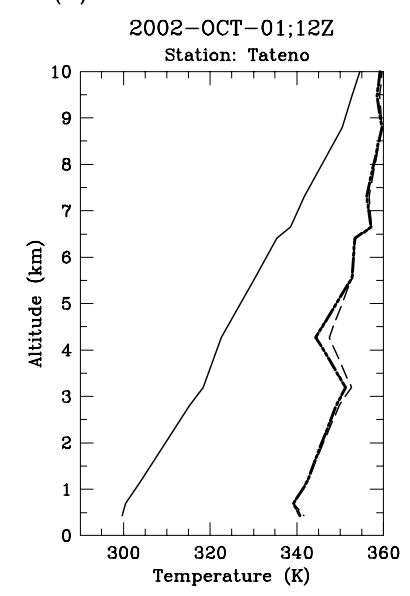

(b)

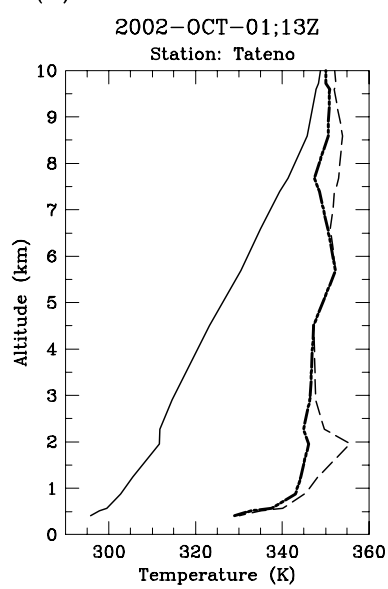

Fig. 8. Vertical profiles of potential temperature $(\theta$; solid), equivalent potential temperature $\left(\theta_{e}\right.$; bold), and saturated equivalent potential temperature $\left(\theta_{e}^{*}\right.$; dashed) at Tateno $(\mathrm{S})$ station at (a) 21:00 and (b) 22:00 LT on 1 October. The distance from the TC center to (a) and (b) was about $20 \mathrm{~km}$ in the front side and $80 \mathrm{~km}$ in the rear side, respectively. The small difference of $\theta_{e}$ and $\theta_{e}^{*}$ at every height indicates the high humidity.

associated with the large precipitating particles and the developed (or developing) clouds. Above 5-km height, where relatively strong echos were observed and the temperature was below $0^{\circ} \mathrm{C}$, weak downdraft was also observed. This may show that small frozen particles fell down or weak downdraft existed there. These characteristics are also seen at Katsuura in Fig. 7, especially when relatively strong inflow and the cyclonic wind were caused by the strong TC circulation.

After the passage of the main rainbands (Region 2), the cyclonic wind was quite weak relative to that in Region 1, and as shown in Fig. 6, a weak cyclonic wind was found. Particularly within about $30 \mathrm{~km}$ from the TC center, a weak cyclonic and radial wind was observed. Weak updraft and downdraft was clear above and below the 3-km height, respectively. On the other hand, at Katsuura (B) station (Fig. 7), a pronounced updraft was seen in all layers below 6-km height. This updraft was stronger than that at Mito (A), which was also associated with strong vorticity. In Region 2, echo intensity was weak relative to that in Region 1 , so there was little rain. The operational weather radar of JMA also observed little rain around Mito, Katsuura, and Tateno stations in Region 2, as shown in Fig. 5. A saturated but stable layer existed below the 3.2-km level, judging from $\theta_{e}$ and $\theta_{e}^{*}$ profiles in Fig. 8a, which were obtained by the radiosonde observation 
at Tateno and located about $20 \mathrm{~km}$ in the front side of the TC. Therefore, an updraft in Region 2 was made by not the convection, but by the TC. Even if an updraft existed and the humidity was high, because the thermal stratification was stable, clouds in Region 2 were not developed. On the other hand, a high humidity layer was observed in almost all layers. Therefore, an updraft transported water vapor from the lower height to the higher height.

To summarize the TC structure in its front side, both comparison between these two stations and the association with the wind changes and the in-situ profiles of temperature and humidity made it clear that the updraft in Region 2 played an important role for transportation of the moist air from the lower layer to the upper layer. It was also revealed that the moist air was transported from the outside region with inflow in the lower troposphere to the outside with outflow in the middle and upper troposphere. It is considered that the rainfall in the front side of the TC was caused by falling frozen particles from the upper-troposphere, which were transported from the inner side of the TC. That circulation was stronger at Katsuura (B) station than that at Mito (A) station because of the strong TC vorticity.

After the passage of the TC center in Region 2, outflow toward the rainband in Region 3 was strong, especially below $3 \mathrm{~km}$ height, as shown in Fig. 6. However, inflow and outflow were found below and above $4 \mathrm{~km}$ height, respectively, in Fig. 7, that is in the inner side of the rainband in Region 3, horizontal convergence and divergence zones were formed at Mito and Katsuura stations, respectively.

After the passage of Region 3, outflow was observed in the middle and lower troposphere. This outflow was especially strong below the $3-\mathrm{km}$ height in the inner edge of the high radar reflectivity region (Fig. 6) located in the southwest quadrant of the TC center. The characteristic mentioned above is not observed in Fig. 7, and the height of the high echo intensity region was relatively low, and outflow was weak in Region 3.

In Fig. $8 \mathrm{~b}$, the humidity was high below $1 \mathrm{~km}$ when a radiosonde was launched at about $80 \mathrm{~km}$ in the rear side of the TC center. Active convection existed above the high humidity layer from the $\theta_{e}$ profile, and therefore, the relatively dry layer in the height range 1 to $3 \mathrm{~km}$ did not mean the existence of dry air advection. It is considered that the convection was active and the humidity was high in almost all layers. Since the TC approached within $13 \mathrm{~km}$ of Mito station, the thermal and water vapor profiles at Tateno station were compared with the wind profile at Mito. High humidity was seen in an outflow region and then flew into the rainband in Region 3. The outflow was strong, especially below the $3-\mathrm{km}$ height. Such a strong outflow in the lower troposphere was not observed at Katsuura, and, therefore, the strong outflow contributed to the intensification of the rainband in Region 3.

\section{Concluding remarks}

The two wind profilers' and rawinsonde observations regarding the TC, Typhoon Higos (0221) made it clear that water vapor was continuously transported from the lower troposphere to the upper troposphere, and that the stronger the TC vorticity was, the stronger the secondary radius-height circulation was. While the TC approached, convective precipitating clouds passed successively over the station that was located in the north side of the TC. At the same time, relatively strong inflow and outflow were observed in the lower troposphere and upper troposphere, respectively. In particular, outflow and weak downdraft were seen above $5 \mathrm{~km}$ height. The latter was associated with the falling of frozen particles. This means that the rainbands in the front side of the $\mathrm{TC}$ were formed from the rain particles coming from the TC center region. After the passage of the TC center, a spiral rainband was well developed, and by comparison between the profiler observations, it is considered that the development of the rainbands was due to the convergence of radial wind at the inner side of the rainbands. This is the first time these characteristics of the secondary circulation and the association of rainbands with radial convergence are directly observed by wind profilers.

Acknowledgements. The authors thank M. Ishihara, Y. Kato, and Y. Izumikawa of the Japan Meteorological Agency for providing the WINDAS data. We also thank T. Kato, S. Hayashi, and M. Yoshizaki of the Meteorological Research Institute, Japan Meteorological Agency for their useful instruments and help. The first author (M. Teshiba) is supported by a grant (15005136) of the Japan Society for the Promotion of Science (JSPS) under the Fellowships for Japanese Junior Scientists. The present study was financially supported by Scientific Grants-in Aids (15005136) of the Ministry of Education, Culture, Sports, Science and Technology of Japan.

Topical Editor O. Boucher thanks two referees for their help in evaluating this paper.

\section{References}

Harr, P. A. and Elsberry, R. L.: Structure of a mesoscale convective system embedded in Typhoon Robyn during TCM-93, Mon. Weath. Rev., 124, 634-652, 1996.

Ishihara, M. and Goda, H.: Operational $1.3 \mathrm{GHz}$-wind profiler network of Japan Meteorological Agency, Proceedings of the Ninth International Workshop on Technical and Scientific Aspects of MST Radar, Toulouse, 13-18 March 2000, 538-540, 2000.

Ishihara, M., Yanagisawa, Z., Sakakibara, H., Matsuura, K., and Aoyagi, J.: Structure of a typhoon rainband observed by two Doppler radars, J. Meteor. Soc. Japan, 64, 923-939, 1986.

Ishihara, M., Fukao, S., and Hashiguchi, H.: The wind profiler network of Japan Met Agency, Abstracts of the Tenth International Workshop on Technical and Scientific Aspects of MST/ST Radar, Piura, Peru, 13-20 May 2003, 134, 2003.

Jorgensen, D. P.: Mesoscale and convective-scale characteristics of mature hurricanes, Part I: General observations by research aircraft, J. Atmos. Sci., 41, 1268-1285, 1984a. 
Jorgensen, D. P.: Mesoscale and convective-scale characteristics of mature hurricanes, Part II: Inner core structure of hurricane Allen (1980), J. Atmos. Sci., 41, 1287-1311, 1984b.

Marks Jr., D. F. and House Jr., R. A.: Inner core structure of hurricane Alicia from airborne Doppler radar observation, J. Atmos. Sci., 44, 1296-1317, 1987.

Powell, M. D.: Boundary layer structure and dynamics in outer hurricane rainbands, Part I: Mesoscale rainfall and kinematic structure, Mon. Wea. Rev., 118, 891-917, 1990a.

Powell, M. D.: Boundary layer structure and dynamics in outer hurricane rainbands, Part II: Downdraft modification and mixed layer recovery, Mon. Wea. Rev., 118, 918-938, 1990 b.

Ryan, B. F., Barnes, G. M., and Zipser, E. J.: A wide rainband in a developing tropical cyclone, Mon. Weath. Rev., 120, 431-447, 1992.

Sakakibara, H., Ishihara, M., and Yanagisawa, Z.: Structure of a typhoon rainstorm in the middle latitudes observed by Doppler radar, J. Meteor. Soc. Japan, 63, 901-922, 1985.
Shapiro, L. J. and Willoughby, H. E.: The response of balanced hurricanes to local sources of heat and momentum, J. Atmos. Sci., 39, 378-394, 1982.

Shibagaki, Y., Yamanaka, M. D., Kita-Fukase, M., Hashiguchi, H., Maekawa, Y., and Fukao, S.: Meso- $\alpha$-Scale wind fields and precipitating clouds in Typhoon 9426 (Orchid) observed by the MU radar, J. Meteor. Soc. Japan, 81, 211-228, 2003.

Tabata, A., Sakakibara, H., Ishihara, M., Matsuura, K., and Yanagisawa, Z.: A general view of the structure of Typhoon $8514 \mathrm{ob}-$ served by dual-Doppler radar - From outer rainbands to eyewall clouds, J. Meteor. Soc. Japan, 70, 897-917, 1992.

Teshiba, M., Hashiguchi, H., Fukao, S., and Shibagaki, Y.: Typhoon 9707 observations with the MU radar and L-band boundary layer radar, Ann. Geophys., 19, 925-931, 2001.

Willoughby, H. E., Marks, Jr., F. D., and Feinberg, R. J.: Stationary and moving convective bands in Hurricanes, J. Atmos. Sci., 41, 3189-3211, 1984. 